\title{
POR UMA EDUCAÇÃO INCLUSIVA: DESAFIOS DO TRANSTORNO DE DÉFICIT DE ATENÇÃO COM HIPERATIVIDADE
}

\section{For an inclusive education: challenges of the attention deficit disorder with hyperactivity}

\author{
Victória Caroline Vidal ${ }^{1}$ https://orcid.org/0000-0003-0778-0559 \\ Carlos Daniel Rodrigues de Oliveira ${ }^{2}$ https://orcid.org/0000-0003-3932-9033 \\ Bruna França Oliveira ${ }^{3}$ https://orcid.org/0000-0001-8987-510X \\ Carla Milena de Moura Laurentino ${ }^{4}$ https://orcid.org/0000-0003-2844-3260 \\ Rahyan de Carvalho Alves ${ }^{5}$ https://orcid.org/0000-0001-7225-5959
}

\footnotetext{
${ }^{1}$ Graduanda em Licenciatura em Geografia - UNIMONTES. Bolsista de Iniciação Científica - CNPq. E-mail: victoria.caroline.vidal.13@gmail.com

${ }^{2}$ Graduando em Licenciatura em Geografia - UNIMONTES. Bolsista de Iniciação Científica - CNPq. E-mail: danielroliv82@gmail.com

${ }^{3}$ Graduanda em Licenciatura em Geografia - UNIMONTES. Bolsista de IC - BIC Unimontes. E-mail: brunaf2011@gmail.com

${ }^{4}$ Graduanda em Licenciatura em Geografia - UNIMONTES. Bolsista de IC - BIC Unimontes E-mail: carlamilenaml@gmail.com

${ }^{5}$ Doutorando em Geografia pela Universidade Federal de Minas Gerais e Professor efetivo da disciplina Estágio Curricular Supervisionado em Geografia - UNIMONTES. E-mail: rahyan.alves@unimontes.br
}

\begin{abstract}
Resumo
O Transtorno do Déficit de Atenção com Hiperatividade - TDAH - é um transtorno neurobiológico de causas genéticas, também podendo ser originado pelo ambiente de convívio da criança/jovem. Tem como características básicas a desatenção, agitação e impulsividade. Diante a importância dessa temática, o presente trabalho busca elucidar estratégias pedagógicas para maximizar o potencial de aprendizagem da criança/jovem com TDAH, medidas que a família pode adotar frente a comportamentos desafiadores e a contribuição do psicólogo neste contexto. Para tanto, utilizou-se como metodologia retrabalhamento bibliográfico, além da vivência e experiência a partir das aulas e da imersão no Estágio Curricular Supervisionado em Geografia na Universidade Estadual de Montes Claros e, também, por meio do fomento de discussões em encontro científico que trata sobre a Educação. Enfatizamos a importância do diagnóstico precoce para o encaminhamento a um tratamento adequado para melhorar o desempenho escolar e, consequentemente, amenizar os impactos emocionais, psicológicos e sociais na vida do indivíduo.
\end{abstract}

Palavras-chave: TDAH; Educação Inclusiva; Escola; Psicologia.

\begin{abstract}
Attention Deficit Hyperactivity Disorder - ADHD - is a neurobiological disorder of genetic causes, which can also be caused by the child's / youngster's living environment. Its basic characteristics are inattention, agitation and impulsivity. Given the importance of this theme, the present study seeks to elucidate pedagogical strategies to maximize the learning potential of children / young people with ADHD, measures that the family can adopt in the face of challenging behaviors and the contribution of
\end{abstract}


Por uma educação inclusiva: desafios do Transtorno de Déficit de Atenção com Hiperatividade Victória Caroline Vidal; Carlos Daniel Rodrigues de Oliveira; Bruna França Oliveira; Carla Milena de Moura Laurentino; Rahyan de Carvalho Alves

the psychologist in this context. To this end, bibliographic rework was used as methodology, in addition to the experience and experience from classes and immersion in the Supervised Curricular Internship in Geography at the State University of Montes Claros and, also, by promoting discussions at scientific meetings that deal with Education. We emphasize the importance of early diagnosis for referral to appropriate treatment to improve school performance and, consequently, mitigate the emotional, psychological and social impacts on the individual's life.

Keywords: TDAH; Inclusive education; School, Psychology.

\section{Introdução}

O Transtorno do Déficit de Atenção com Hiperatividade - TDAH - é um transtorno que deriva da influência de fatores genéticos e/ou ambientais, consistindo em um transtorno neurobiológico multifatorial e crônico. O TDAH, por vezes denominado de Distúrbio do Déficit de Atenção - DDA - tem como características básicas: desatenção, agitação e a impulsividade.

Os primeiros indicativos do transtorno geralmente são observados quando a criança está em idade escolar, podendo perdurar por toda a vida. Os sintomas podem prejudicar consideravelmente a aprendizagem do aluno, por isso, faz se necessário o esclarecimento do que é este transtorno e suas implicações aos pais e educadores. Por não se tratar de uma doença, não há cura, mas sim estratégias pedagógicas elaboradas por educadores; tratamentos desenvolvidos por especialistas, como o psicólogo, além de medidas que a família pode adotar frente a comportamentos desafiadores, para a obtenção de melhores resultados no processo de aprendizagem.

Diante da dificuldade em distinguir indisciplina com as manifestações comportamentais do TDAH, o presente estudo tem por objetivo elucidar sobre este transtorno, estratégias pedagógicas para maximizar o potencial de aprendizagem da criança/jovem com TDAH e a contribuição do psicólogo, enfatizando a importância do diagnóstico precoce para o encaminhamento a um tratamento adequado para amenizar os impactos emocionais, psicológicos e sociais na vida do indivíduo.

A metodologia utilizada consiste em retrabalhamento bibliográfico das temáticas: educação inclusiva, Transtorno do Déficit de Atenção, estratégias pedagógicas e contribuições dos psicólogos para melhorar o rendimento escolar do aluno portador do TDAH, a partir dos autores Barbosa, 2015; Barini; Hage, 2015; Ferreira; Prado; Cadavieco, 2015; Borella, 2002, dentre outros. Além da vivência e experiência a partir das aulas, da imersão no Estágio Curricular Supervisionado em Geografia promovida pelos autores na Universidade Estadual de Montes Claros (Unimontes) e a partir do fomento dos debates realizados no XII Encontro Internacional de Formação de Professores e Estágio Curricular Supervisionado - ocorrido no 
Por uma educação inclusiva: desafios do Transtorno de Déficit de Atenção com Hiperatividade Victória Caroline Vidal; Carlos Daniel Rodrigues de Oliveira; Bruna França Oliveira; Carla Milena de Moura Laurentino; Rahyan de Carvalho Alves

ano de 2019 - na Universidade Federal de Uberlândia (evento realizado por três instituições Públicas de Ensino Superior, a saber: a UFU, a Universidade de Brasília (UNB) e pela Unimontes. Esta última representada por meio dos Professores do Departamento de Estágios e Prática Escolares e pelo Núcleo de Estágio Curricular Supervisionado).

\section{Dificuldades de Aprendizagem, Transtornos de Aprendizagem e o TDAH}

O Transtorno do Déficit de Atenção com Hiperatividade por ser um transtorno identificado, principalmente, em crianças e adolescentes que estão na fase de desenvolvimento escolar, comumente, é confundido com: as dificuldades de aprendizagem e os transtornos de aprendizagem. Mas, estes são diferentes, sugerindo diagnósticos e tratamentos adequados para cada situação.

Quando um aluno não acompanha o conteúdo ministrado em sala de aula ao mesmo tempo dos demais colegas, associa-se a uma dificuldade de aprendizagem. Termo genérico referente a um atraso na obtenção e/ou realização de uma ou mais atividades, sem uma determinada causa. A utilização do termo dificuldade de aprendizagem não faz referência à origem dela ou às suas características, mas apenas a um indício; está afirmando que há algo inconsistente no processo de aprendizagem de determinado aluno. A dificuldade de aprendizagem abrange desde problemas motores ou disfunções neurológicas até problemas externos, a saber: problemas emocionais, familiares, puberdade, dentre outros que podem contribuir para queda do desempenho escolar (BORELLA, 2002).

Já os transtornos de aprendizagem caracterizam-se por serem disfunções no cérebro que prejudicam o desenvolvimento escolar do aluno, isto é, funções específicas que o cérebro não consegue executar normalmente, conforme esperado em crianças/jovens da mesma faixa etária. A Dislexia é um exemplo de transtorno de aprendizagem considerada um transtorno específico de origem neurobiológica, caracterizada por dificuldade no reconhecimento preciso e/ou fluente da palavra, na habilidade de decodificação e em soletração. Essas dificuldades geralmente resultam de um déficit no componente fonológico da linguagem e outras habilidades cognitivas (MAIA; CONFORTIN, 2015).

Diante disso, o TDAH não é um transtorno de aprendizagem direto, pois não atinge focalmente o processo de aprendizagem do aluno. Porém, os seus sintomas podem atrapalhar significativamente o processo de ensino-aprendizagem e a convivência da criança e adolescente no âmbito escolar e social. 
Por uma educação inclusiva: desafios do Transtorno de Déficit de Atenção com Hiperatividade Victória Caroline Vidal; Carlos Daniel Rodrigues de Oliveira; Bruna França Oliveira; Carla Milena de Moura Laurentino; Rahyan de Carvalho Alves

\section{Transtornos do Neurodesenvolvimento}

O TDAH é um transtorno neurobiológico, de causas genéticas, também podendo ser originado pelo ambiente de convívio da criança/jovem. Quanto ao aspecto neurobiológico, a parte do córtex pré-frontal demora a se desenvolver, sendo menor em pessoas portadoras deste transtorno. Esta parte do cérebro é responsável por ações como atenção, planejamento, impulsividade dentre outras (SPINNLER; CAMPOS; MATOS, 2019).

O TDAH pode ser encontrado, geneticamente, em genes que regulam a oferta de dopamina e serotonina, hormônios presentes no corpo humano (BORELLA, 2002). Ainda em consonância com o Borella (2002), além de fatores biológicos, que não são genéticos, têm-se também: uso de álcool, drogas e certos medicamentos durante a gestação, nascimentos prematuros, hemorragias intracranianas e falta de oxigênio durante o parto. Há também fatores relacionados ao ambiente que interferem no desenvolvimento psicológico e emocional, a exemplos de: conflitos familiares, baixa condição socioeconômica, transtorno mental nos pais, envolvimento dos familiares em atos de violência e criminalidade, entre outros (BORELLA, 2002).

Segundo o Manual Diagnóstico de Transtornos Mentais - DSM - V (2014), o TDAH surge entre os 5 e 12 anos de idade, podendo ser classificado em Leve, Moderado e Grave. É caracterizado pela presença de três grupos de sintomas: predominantemente desatento, predominantemente hiperativo-impulsivo e o combinado, "referente aos dois grupos hiperativo e desatento, sendo o mais grave devido à amplitude dos sintomas, causando maior prejuízo à vítima” (SPINNLER; CAMPOS; MATOS, 2019, p. 2).

O TDAH apesar de não se caracterizar como um transtorno de aprendizagem direto traz consigo a desatenção e a inquietude, fatores que afetam o foco e causa queda de rendimento escolar. As crianças portadoras deste transtorno tendem a não aceitar os métodos padronizados de ensino ou modelos educacionais rígidos, necessitando de práticas pedagógicas criativas, adaptáveis e que demonstre segurança em seu ambiente escolar.

As crianças/jovens com TDAH são descritas por pais, educadores e colegas como aqueles que são inquietos, desorganizados, desatentos, que falam de maneira excessiva ou apresentam timidez extrema; agitados agem de maneira impulsiva, impacientes e, muitas vezes, não finalizam o que começam, apresentando dificuldades no relacionamento com os colegas e têm constantes episódios de esquecimento, inclusive dos próprios pertences. Além de ter casos em que a criança reluta em obedecer a ordens e seguir regras, apresentando comportamento inadequado comparado às demais crianças da mesma faixa etária. Por isso, exigem maior atenção e cuidado dos pais e educadores (CADIMA, 1996). 
Por uma educação inclusiva: desafios do Transtorno de Déficit de Atenção com Hiperatividade

Victória Caroline Vidal; Carlos Daniel Rodrigues de Oliveira; Bruna França Oliveira; Carla Milena de Moura Laurentino; Rahyan de Carvalho Alves

O comportamento atípico da criança/jovem com TDAH, por vezes, é confundido com falta de educação, sendo rotulados como "pirracentos", "bagunceiros", inquietos, dentre outros, implicando no isolamento, por se sentir rejeitado pelos colegas, acarretando baixa autoestima também devido às constantes críticas e punições por causa do modo como realizam suas atividades (MAIA; CONFORTIN, 2015).

O TDAH apresenta três características básicas que merecem a nossa atenção, sendo essas: a distração, a agitação e a impulsividade, podendo gerar dificuldades emocionais, de relacionamento familiar e com os colegas e funcionários da escola e no rendimento escolar. A desatenção é evidente quando o portador de TDAH tem o conhecimento do conteúdo de uma determinada prova, mas comete erros por descuido devido à queda em sua atenção. Além disso, "qualquer estímulo é capaz de desviar sua atenção". (OLIVEIRA; FERRARI, 2014, p. $10)$.

O desempenho escolar destas crianças/jovens é quase sempre apontado como baixo pelos educandários, comparado aos demais colegas da turma, em decorrência da dificuldade em se adequar às demandas da escola, sendo frequentes os estudantes com este transtorno terem repetência de ano/série, durante a trajetória escolar, por vezes não concluindo o ensino médio. As implicações deste transtorno, principalmente, no ambiente escolar, tem gerado questionamentos por parte dos educadores, pais e especialistas, pressionando o sistema educacional - desde a escola de ensino regular pública e privada até as universidades/faculdades - e o poder público para medidas efetivas de inclusão de crianças e adolescentes com o TDAH para aprimorar o seu potencial de aprendizagem e amenizar os impactos no desenvolvimento emocional, social, acadêmico e profissional (CADIMA, 1996).

\section{Educação Inclusiva: O Papel da Escola e dos Professores}

A escola precisa desenvolver modelos de aprendizagem voltados ao desenvolvimento das capacidades e potencialidades de alunos que vivem com o transtorno do TDAH, e pais, professores e pedagogos que dialoguem entre si no sentido de garantir um ambiente escolar que seja saudável e oportuno.

A escola tem um papel fundamental na superação das desigualdades sociais e na construção da cidadania, e diante da perspectiva da inclusão é preciso uma ação conjunta entre todos aqueles que fazem parte da comunidade escolar. É necessário enfrentar no âmbito escolar as práticas discriminatórias e criar alternativas para superá-las, para que esta assuma uma postura realmente inclusiva contribuindo para a superação da exclusão presente na 
Por uma educação inclusiva: desafios do Transtorno de Déficit de Atenção com Hiperatividade

Victória Caroline Vidal; Carlos Daniel Rodrigues de Oliveira; Bruna França Oliveira; Carla Milena de Moura Laurentino; Rahyan de Carvalho Alves

sociedade, devendo haver uma mudança estrutural e cultural para que todos os alunos tenham suas especificidades atendidas e respeitadas (FERREIRA; PRADO; CADAVIECO, 2015).

A Educação Inclusiva defende um ambiente de aprendizagem diferenciado e de qualidade para todos os alunos, reconhecendo as diferenças, desenvolvendo-se com a diversidade, enfatizando que todas as crianças devem ser educadas numa escola isenta de barreiras pedagógicas. A escola deve ser aberta a todos, independentemente das dificuldades as crianças/jovens devem aprender juntas, sem distinção. A escola inclusiva, em consonância com Ferreira, Prado e Cadavieco (2015) é:

[...] a escola inclusiva pretende não só integrar a criança no ambiente 'normal' da escola, mas visa principalmente criar 'uma escola para todos', com respeito pela 'diferença', proporcionando 'igualdade de oportunidades' para todas as crianças, quer seja ou não portadoras de deficiências (FERREIRA; PRADO; CADAVIECO, 2015, p. 4).

Então, o objetivo da escola inclusiva é atender à diversidade com ensino de qualidade, devendo ser uma instituição que aceita as diferenças entre os alunos e promova ações e práticas educacionais, adaptando-as às diferenças de capacidades, características e necessidades de cada um. (FERREIRA; PRADO; CADAVIECO, 2015). Nesse contexto, a filosofia da escola inclusiva é pautada na concepção dos direitos humanos, sendo a igualdade e respeito à diferença valores indissociáveis que colaboram no processo de equidade social, devendo reduzir a exclusão dentro e fora da escola.

A Constituição Federal Brasileira de 1988, referente à educação inclusiva, prevê:

Art. 208. O dever do Estado com a educação será efetivado mediante a garantia de: III - atendimento educacional especializado aos portadores de deficiência, preferencialmente na rede regular de ensino. (BRASIL, 1998).

Sobre o TDAH e a dislexia, o Projeto de Lei do Senado n 402 de 2008 dispõe sobre o diagnóstico e o tratamento na educação básica como exposto a seguir:

Art. $1^{\circ} \mathrm{O}$ poder Público deve manter programa de diagnóstico e tratamento de estudantes da educação básica com dislexia e Transtorno de Déficit de Atenção com Hiperatividade - TDAH.

Art. $2^{\circ} \mathrm{O}$ diagnóstico e o tratamento de que o art. $1^{\circ}$ deve ocorrer por meio de equipe multidisciplinar, da qual participarão, entre outros, educadores, psicólogos, psicopedagogos, médicos e fonoaudiólogos.

Art. $3^{\circ}$ As escolas de Educação básica devem assegurar às crianças e aos adolescentes com dislexia e TDAH o acesso aos recursos didáticos adequados ao desenvolvimento de sua aprendizagem.

Art. $4^{\circ}$ Os sistemas de ensino devem garantir aos professores da educação básica cursos sobre diagnóstico e o tratamento da dislexia e do TDAH, de forma a facilitar o trabalho da equipe multidisciplinar de que trata o art. $2^{\circ}$. 
Por uma educação inclusiva: desafios do Transtorno de Déficit de Atenção com Hiperatividade

Victória Caroline Vidal; Carlos Daniel Rodrigues de Oliveira; Bruna França Oliveira; Carla Milena de Moura Laurentino; Rahyan de Carvalho Alves

As Diretrizes Nacionais para a Educação Especial são instituídas a partir da Resolução CNE/CBE no 2 de 11 de setembro de 2001, e aponta que:

\begin{abstract}
Art. $5^{\circ}$ Consideram-se educandos com necessidades educacionais especiais os que, durante o processo educacional, apresentarem: I - dificuldades acentuadas de aprendizagem ou limitações no processo de desenvolvimento que dificultem o acompanhamento das atividades curriculares, compreendidas em dois grupos: a) aquelas não vinculadas a uma causa orgânica específicas; b) aquelas relacionadas a condições, disfunções, limitações ou deficiências; II - dificuldades de comunicação e sinalização diferenciadas dos demais alunos, demandando a utilização de linguagens e códigos aplicáveis; III - altas habilidades/superdotação, grande facilidade de aprendizagem que o leve a dominar rapidamente conceitos, procedimentos e atitudes (BRASIL, 2001).
\end{abstract}

O aluno com TDAH, bem como os que possuem deficiência intelectual, física ou outro transtorno, precisam de uma atenção especial do educador. Por isso, a Lei de Diretrizes e Bases - LDB $n^{\circ}$ 9.394/96 - assegurou aos alunos com necessidades especiais o direito a currículos, métodos, recursos educativos e de organização específicos; e junto ao Estatuto da Criança e do Adolescente - ECA -, por meio da Lei ${ }^{\circ} 8.069$ estabelece o direito às pessoas com deficiências em receber educação, preferencialmente na rede regular de ensino (OLIVEIRA; FERRARI, 2014).

O conceito de deficiência e o entendimento direcionado a crianças e jovens em idade escolar evoluíram com o passar dos anos, passando a enfatizar não a deficiência física e cognitiva em si, mas as dificuldades particulares do indivíduo direcionado ao ambiente, a sua condição social e cultural, e como o sujeito lida com tal processo (analisando, em paralelo, a capacidade de carga emocional e o poder de resiliência) (FERREIRA; PRADO; CADAVIECO, 2015).

A evolução deste conceito deve-se ao estigma presente na educação - distinção entre o normal e o portador de deficiência. À vista disso, propõem-se o conceito de crianças com Necessidades Educativas Especiais - NEE -, compreendidos como aqueles que apresentam dificuldades (sensorial, físico, intelectual, emocional ou social) de aprendizagem no período de sua escolarização, necessitando de uma atenção especializada e maiores recursos educacionais. $\mathrm{O}$ cuidado que o professor deve ter ao empregar este termo é para não fazer a exclusão dos incluídos e gerar constrangimento e inibição deles em sala de aula. (FERREIRA; PRADO; CADAVIECO, 2015).

A Declaração de Salamanca, em 1994, concebe o conceito de crianças/jovens com NEE, como: 
Por uma educação inclusiva: desafios do Transtorno de Déficit de Atenção com Hiperatividade

Victória Caroline Vidal; Carlos Daniel Rodrigues de Oliveira; Bruna França Oliveira; Carla Milena de Moura Laurentino; Rahyan de Carvalho Alves

Todas as crianças e jovens cujas necessidades se relacionam com deficiências ou dificuldades escolares e consequentemente têm necessidades educativas escolares em algum momento da sua vida escolar (Declaração de Salamanca, 1994, p. 17)

O professor, comumente, é o primeiro a identificar os sintomas do TDAH no aluno em vista a dificuldade em apreender o conteúdo ministrado, por isso precisa criar estratégias metodológicas para que a dificuldade não afete a autoestima do aluno a ponto de se sentir inferior aos demais. Além disso, os professores devem ver os alunos com TDAH não como aqueles que dificultam o desenvolvimento processual e crítico da aula, mas sim como aqueles que podem ao seu modo, contribuir para fazer da sua aula mais plural (MAIA; CONFORTIN, 2015).

Alguns professores possuem o domínio do conteúdo, mas não sabem aplicar metodologias que atenda todos os alunos de uma sala, assim, ao não proporcionar o envolvimento e interação com todos, àqueles que possuem TDAH se sentem incompreendidos e até segregados frente aos demais colegas, desmotivando-os.

A inclusão não é o professor aplicar testes diferentes a um aluno que possui dificuldades e não sabe responder semelhante aos demais, não é o aluno trabalhar com a professora de apoio - dentro ou fora da sala de aula - uma atividade que não possui relação com as que estão sendo desenvolvidas com o restante da turma. Não é a concessão de privilégios aos portadores de deficiências. É aprender no grupo e com o grupo, em situações de verdadeira aprendizagem e cooperação, tornando o aluno dito "diferente" responsável por seu conhecimento e aprendizagem. O desenvolvimento de trabalhos cooperativos desestimula no âmbito escolar a competição, incentivando-se a cooperação, ao privilegiar práticas em grupo, ao invés de individual, contribuindo para a melhora do desempenho escolar (RIBEIRO, 2018).

A superação de preconceitos e discriminações não ocorre apenas colocando na mesma sala estudantes que apresentem aspectos culturais ou condições diversas, mas sim a interação positiva, responsável e dinâmica contribuirá para a erradicação dessas mazelas sociais. Neste entendimento, o professor é um dos principais personagens no processo da educação inclusiva e ao planejar a sua prática docente, especialmente ao realizar atividades, estas não devem ser elaboradas de igual teor e nível de compreensão, mas deve ser colocado em pauta o desenvolvimento operacional e cognitivo das tarefas que venham atender todos os alunos, disponibilizando situações adequadas de aprendizagem (CADIMA, 1996).

Os professores que têm o conhecimento sobre o transtorno conseguem ser mais assertivos em sua metodologia de ensino, preparando aulas com estratégias pedagógicas que instigam os alunos a participar da aula, evitando que se distraiam com facilidade e criando um 
Por uma educação inclusiva: desafios do Transtorno de Déficit de Atenção com Hiperatividade Victória Caroline Vidal; Carlos Daniel Rodrigues de Oliveira; Bruna França Oliveira; Carla Milena de Moura Laurentino; Rahyan de Carvalho Alves

ambiente de respeito às diversidades. Por isso, é preciso a elaboração de estratégias eficazes na absorção de conhecimentos (FERREIRA; PRADO; CADAVIECO, 2015).

No caso do TDAH, para que o aluno consiga apreender melhor o conteúdo ministrado, é importante conceder pequenos intervalos e instigar os alunos a participar ativamente, incentivando a expor seus questionamentos e opiniões, motivando-os. Também preparar as aulas com atividades visuais e auditivas, garantindo que todos tenham a possibilidade de aprender. Além disso, devido a sua fácil distração, recomenda-se que os professores evitem colocá-lo perto de portas e janelas, pois qualquer movimentação ou ruído é o suficiente para fazer o aluno ficar desatento na explanação (RIBEIRO, 2018).

Em consonância com Maia e Confortin (2015) durante a graduação, o professor deveria ter em sua grade curricular uma disciplina que tratasse de deficiências e transtornos a identificação de cada uma e comportamentos típicos -, comuns em sala de aula, e ensinasse como lidar e proceder com esses estudantes em determinadas situações, alterando sua metodologia quando necessário para a inclusão efetiva destes, contribuindo para o diálogo entre o aluno, professor e colegas.

Dessa forma, o professor irá usar a agitação e inquietude do estudante para uma tarefa proveitosa e fará com que ele se sinta útil. A escola deve conceder apoio aos professores promovendo reuniões para que as experiências sejam compartilhadas e dando-lhes suporte para o desenvolvimento do processo de ensino-aprendizagem. Também, precisa estabelecer um diálogo com os pais do estudante com TDAH para que os desafios e conquistas sejam compartilhados. Sobretudo, é necessário a escola perceber o estudante "não apenas como um objeto de trabalho, mas como um indivíduo desafiante e portador de grandes potencialidades" (MAIA; CONFORTIN, 2015, p. 82).

\section{Estratégias para Pais de Crianças/Jovens com TDAH}

Lidar com crianças e jovens com TDAH é uma tarefa complexa para os pais, pois exigem muita atenção e cuidado, devendo acompanhar no dever de casa e comparecer, constantemente, à escola. Essa dinâmica se não bem dialogada e propositiva gera, inclusive, um desgaste, sendo expressos, geralmente, em constantes discussões familiares. A tarefa se torna ainda mais difícil quando o filho desobedece às regras impostas pelos pais, impactando negativamente na relação de ambos e aumentando o estresse (SPINNLER; CAMPOS; MATOS, 2019).

Algumas estratégias podem ser traçadas pelos pais em casa para lidar com o filho portador de TDAH. No âmbito familiar, é aconselhável os pais adotarem como métodos 
Por uma educação inclusiva: desafios do Transtorno de Déficit de Atenção com Hiperatividade Victória Caroline Vidal; Carlos Daniel Rodrigues de Oliveira; Bruna França Oliveira; Carla Milena de Moura Laurentino; Rahyan de Carvalho Alves

educativos os reforços positivos, tendo em vista que devido ao comportamento atípico as crianças se sentem desmotivadas e ressentidas com as constantes reclamações e punições devido ao modo como desempenham suas atividades (SPINNLER; CAMPOS; MATOS, 2019).

Quando estes realizarem uma tarefa corretamente deve-se elogiá-los, ao invés de criticá-los e apontar erros e falhas quando não correspondem às expectativas. Dessa forma, “destacando o lado bom desse indivíduo é possível alcançar algum desempenho e progresso, pois elogios realçam autoestima, enquanto, castigos e críticas geram frustrações" (SPINNLER; CAMPOS; MATOS, 2019, p.12). Juntamente com o reforço positivo, os pais devem estabelecer normas e regras claras e coerentes, impor limites e estabelecer uma educação que não seja muito permissiva.

Os pais devem atentar para os seus comportamentos, por vezes, agravantes do transtorno, como a dificuldade em estabelecer limites aos filhos ou quando estabelecem regras muito rígidas, colaborando para a "desregulação da ansiedade, sensação de frustração e humor irritadiço na criança/adolescente" (SPINNLER; CAMPOS; MATOS, 2019, p.10).

Ressalta-se a pertinência do diálogo entre pais e educadores quanto à quais medidas devem ser tomadas quando os sintomas se manifestarem, não devendo ser estigmatizado e muito menos banalizado por ambas as partes, haja vista se tratar de um transtorno que afeta o desenvolvimento emocional e social. Por isso, é preciso um diagnóstico precoce para evitar consequências negativas (SPINNLER; CAMPOS; MATOS, 2019).

Apesar de o diagnóstico ser realizado por um especialista na área, o educador tem papel fundamental tendo em vista que a escola é o ambiente em que a criança passa a maior parte do tempo e, a partir de observações durante o cotidiano, este pode informar aos pais quanto ao surgimento dos sintomas e direcioná-los a um profissional apto a realizar o diagnóstico preciso e tratamento recomendado da criança/jovem.

\section{O Papel do Psicólogo: Diagnóstico e Tratamento do TDAH}

Os problemas comportamentais que o aluno manifesta no ambiente escolar são tratados, comumente, como indisciplina, devendo ser corrigidos. Acredita-se que quando o aluno por algum motivo não consegue integrar-se ao ambiente escolar é somente culpa dele, não compreendendo a influência dos fatores internos ligados ao neurodesenvolvimento, bem como fatores externos ligados ao ambiente em que a criança/adolescente vive. Assim, as causas dos problemas não são identificadas e, consequentemente, não são solucionadas. 
Por uma educação inclusiva: desafios do Transtorno de Déficit de Atenção com Hiperatividade

Victória Caroline Vidal; Carlos Daniel Rodrigues de Oliveira; Bruna França Oliveira; Carla Milena de Moura Laurentino; Rahyan de Carvalho Alves

Os pais e educadores ao observarem os sintomas do TDAH devem encaminhar a criança/jovem o mais breve possível a especialistas, como o psicólogo, para o diagnóstico e, sendo confirmado, para o tratamento adequado. Entre as possibilidades de tratamento, os estimulantes têm se mostrado eficazes por apresentarem resultados significativos em um prazo curto de tempo, contribuindo no relacionamento com os colegas e aumento do interesse nos estudos. Então, independentemente da fase de desenvolvimento do indivíduo, o tratamento para quem apresenta este transtorno envolve a combinação de medicamentos visando minimizar os sintomas de desatenção, de hiperatividade e de impulsividade, junto à adoção de intervenções psicológicas, "como terapia cognitivo-comportamental - TCC-, onde por meio delas se torna possível desenvolver estratégias para lidar com os sintomas residuais" (OLIVEIRA, 2018, p.1).

Ressalta-se que o não diagnóstico do TDAH implica no atraso escolar desses estudantes por causa da dificuldade em apreender os conteúdos, ocasionando no aumento nos índices de repetência, baixo rendimento escolar, evasão e dificuldades emocionais e sociais.

[...] Uma vez diagnosticado o TDAH, esse aluno deve ser considerado como uma criança com necessidades educacionais especiais, pois para que tenha garantidas as mesmas oportunidades de aprender que os demais colegas de sala de aula, serão necessárias algumas adaptações visando diminuir a ocorrência dos comportamentos indesejáveis que possam prejudicar seu progresso pedagógico [...] (REIS, 2011 p.8).

Há certo desconhecimento, em alguns casos, da própria comunidade escolar em relação à abrangência do trabalho do psicólogo, confundindo a sua atuação no âmbito educacional com o de pedagogo. Assim, deve ser lembrado que o trabalho do psicólogo está relacionado ao comportamento humano, enquanto práticas/ou técnicas que visam à adequação do conhecimento ao intelecto humano referem-se a práticas pedagógicos, sendo de responsabilidade do pedagogo identificá-las e aplicá-las, isso em parceria com a equipe de professores. A importância do psicólogo na aprendizagem se faz necessária quando o comportamento do aluno interfere diretamente no seu rendimento escolar como, por exemplo, a falta de atenção. O trabalho do psicólogo é a identificação dos motivos da desatenção do aluno e não o baixo rendimento escolar em si (OLIVEIRA, 2018).

Deste modo, é passível, através de intervenções psicológicas, como terapias comportamentais, obter-se resultados satisfatórios que condicionam melhor desempenho escolar dessas crianças e jovens, contribuindo para o progresso de suas habilidades e potencialidades e, consequentemente, sua inclusão social. Em decorrência da complexidade do transtorno e as diversas implicações, o acompanhamento e o processo de tratamento do TDAH requer ação interdisciplinar, englobando, além dos psicólogos, médicos, 
Por uma educação inclusiva: desafios do Transtorno de Déficit de Atenção com Hiperatividade Victória Caroline Vidal; Carlos Daniel Rodrigues de Oliveira; Bruna França Oliveira; Carla Milena de Moura Laurentino; Rahyan de Carvalho Alves

psicopedagogos, neuropsicólogos e fonoaudiólogos, juntamente com o apoio familiar (RIBEIRO, 2018).

\section{A Importância do Estágio Curricular Supervisionado frente ao TDAH}

No espaço acadêmico o estágio possibilita a convivência com alunos portadores de TDAH, possibilitando que o estudante, e futuro professor, desenvolva maior conhecimento e habilidades para lidar com as diversas situações em sala de aula. Pois, cabe ressaltar que este será o seu espaço de atuação.

O estágio proporciona a relação do acadêmico com as inúmeras realidades trazidas de cada aluno, somada a experiência profissional do professor do estágio. Esse conhecimento e interação tem como consequência um profissional mais preparado a lidar com as dificuldades encontradas em sala de aula, como o desafio que é trabalhar com alunos com TDAH (SCALABRIN, 2013; SANTOS e MATOS, 2017).

Dessa forma, o estágio antecede o convívio com esses alunos e prepara os acadêmicos a aprenderem a desenvolver atividades específicas, a chamar a atenção do aluno da melhor forma possível e a promover uma rotina com o estudante, para que ele alcance bons resultados (SOARES e MATOS, 2017). No entanto, cabe ao futuro professor, estar em dia com o estudo de caso, a teoria necessita estar alinhada à prática, para que se tenha uma boa formação do profissional. É importante que o acadêmico esteja previamente consciente do que pode acontecer e da realidade do aluno com TDAH. Assim, a união da teoria e da prática dará uma formação mais consistente e resultará em um profissional ainda mais qualificado (ROSA et al., 2012)

Ressalta-se a importância para a formação dos docentes em relação à educação especial, pois o conhecimento acerca das necessidades e recursos adequados para atender esses alunos será relevante na formação deles e faz parte do compromisso profissional e ético do docente (MIKKELSEN, 1980; apud RIBEIRO, 2015).

O estágio curricular supervisionado destaca-se como uma disciplina estratégica e que transversa na articulação entre teoria e prática, sendo essencial e importante na formação dos professores, pois através desta que o futuro profissional conhece os aspectos indispensáveis para a formação da construção da identidade e dos saberes docente no dia-a-dia (PIMENTA; LIMA, 2004). É o momento do contato dos acadêmicos com a pluralidade de alunos que se encontram nas escolas, dentre eles aqueles que necessitam da educação especial, destacado aqui os que vivem com o transtorno do TDAH. 
Por uma educação inclusiva: desafios do Transtorno de Déficit de Atenção com Hiperatividade

Victória Caroline Vidal; Carlos Daniel Rodrigues de Oliveira; Bruna França Oliveira; Carla Milena de Moura Laurentino; Rahyan de Carvalho Alves

No âmbito do estágio é possível desenvolver atividades que trabalhem as demandas educacionais destes alunos a partir da introdução de novas metodologias de ensino. O lúdico se apresenta como um processo que chama a atenção e incentiva os alunos a participarem das atividades, a exemplos de brincadeiras, jogos e representações que são pedagogicamente importantes na atenuação dos problemas característicos do aluno com o transtorno. Por meio das atividades o educando "compreende regras sociais, consegue deter impulsos e se concentrar" (RIBEIRO, 2018).

Quanto mais frequente e preparado for o contato com os alunos, maior será o resultado profissional desse acadêmico, que poderá estar mais apto a trabalhar e, até mesmo, terá um olhar mais crítico e sensível para identificar as necessidades e os limitações do estudante, e tal processo poderá resultar em bons resultados, tanto para o aluno, quanto para o professor. Além disso, o estágio proporciona o contato com outros profissionais e serve como um momento de reflexão e crítica a si mesmo, evitando que medidas equivocadas sejam tomadas.

\section{Considerações Finais}

Em muitos casos os educadores não sabem lidar com estudantes que possuem hiperatividade, fazendo um pré-julgamento e confundindo o TDAH com mau comportamento, prejudicando, significativamente, a aprendizagem dos alunos. Quando não tratado da forma devida pode acarretar diversas consequências emocionais, sociais e psicológicas. Essa situação é preocupante, "pois é no ambiente escolar que a maioria dos jovens têm contato com a leitura e a escrita, exigindo sua concentração e atenção". (MAIA; CONFORTIN, 2015, p.74). Fazendo importante destacar que o TDAH não é oriundo de falhas educacionais e sim de fatores biológicos.

Os pais devem estabelecer diálogos com a escola para tomarem o conhecimento do TDAH e receberem auxílio e orientações de como lidar com determinadas situações e comportamentos inadequados para o contexto inserido, devendo estabelecer normas e regras claras e coerentes, impondo limites e estabelecer uma educação que não seja permissiva.

No seio familiar é essencial a paciência e compreensão para lidar com crianças/jovens com TDAH. O reforço positivo é uma possível estratégia de correção dos comportamentos inadequados, haja vista evidenciar os acertos e evitar punições, favorecendo um desenvolvimento saudável.

A adoção de práticas pedagógicas inclusivas e o esclarecimento deste e demais transtornos no âmbito acadêmico, possibilita a construção de uma sociedade que cultiva os princípios de igualdade, isonomia, respeito às diversidades e solidariedade. As crianças e 
Por uma educação inclusiva: desafios do Transtorno de Déficit de Atenção com Hiperatividade Victória Caroline Vidal; Carlos Daniel Rodrigues de Oliveira; Bruna França Oliveira; Carla Milena de Moura Laurentino; Rahyan de Carvalho Alves

adolescentes com transtornos precisam de apoio e compreensão de educadores e pais para a obtenção de melhores resultados no seu desempenho escolar e, consequentemente, social e pessoal.

Por fim, o estágio apresenta como um exercício de suma importância para que o acadêmico desenvolva conhecimento e habilidade com a sala de aula e suas inúmeras adversidades. É o momento de contato com a realidade e de aprendizagem, que contribui para uma melhor formação profissional.

\section{Referências}

BARBOSA, Priscila S. Dificuldades de aprendizagem. São Luiz-MA: UemaNet, 2015.

BARINI, Nayara Salomão; HAGE, Simone Rocha De Vasconcellos. Compreensão verbal de escolares com Transtorno do Déficit de Atenção e Hiperatividade, CoDAS. Vol. 27. N.5. 2015 .

BRASIL. Constituição (1988). Constituição da República Federativa do Brasil. Brasília, DF: Senado, 1988.

BRASIL. Ministério da Educação. Secretaria de Educação Especial. Política Nacional de Educação Especial. Brasília: SEESP, 1994.

BRASIL. Lei de Diretrizes e Bases da Educação Nacional. Lei no 9394/96. 1996.

BRASIL. Conselho Nacional de Educação / Câmara de Ensino Básico. Diretrizes Nacionais para a Educação Especial na Educação Básica, Brasília, DF, 2001.

CASTELlAR; Sonia \& VILHENA; Jerusa. Ensino de Geografia. São Paulo: Cengage Learning, 2010, p. 23-42.

CAVALCANTI, Lana de Souza. Cotidiano, mediação pedagógica e formação de conceitos: uma contribuição de Vygotsky ao ensino de geografia. Cad. CEDES, Campinas, v. 25, n. 66, p. 185-207, Aug. 2005.

FERREIRA Marco Paulo Maia; PRADO, Susana Agudo \& CADAVIECO, Javier Fombona. Educação Inclusiva: Natureza e fundamentos. Revista de Educación, 2011.

FERREIRA, Carolina; SAMPAIO, Adriany de Ávila Melo. O ensino de geografia para estudantes com transtorno de déficit de atenção com hiperatividade. 2008, TCC (Geografia) - Universidade Federal de Uberlândia, Uberlândia, 2008.

GLAT, R.; PLETSCH, M. D. O papel da universidade frente às políticas públicas para educação inclusiva. Revista Benjamim Constant, 10(29), 3-8, 2004.

GLAT, Rosana \& FERNANDES, Edicléa Mascarenhas. Da educação segregada à educação inclusiva: uma breve reflexão sobre os paradigmas educacionais no contexto da educação especial brasileira. Revista Inclusão, v. 1, n. 1, p. 35-39, 2005. 
Por uma educação inclusiva: desafios do Transtorno de Déficit de Atenção com Hiperatividade Victória Caroline Vidal; Carlos Daniel Rodrigues de Oliveira; Bruna França Oliveira; Carla Milena de Moura Laurentino; Rahyan de Carvalho Alves

MONTIEL, J. M. \& CAPOVILLA, F. C. (Orgs.). Atualização em transtornos de aprendizagem. São Paulo: Arte Médica, 2009.

NASCIMENTO, Rosangela Pereira de. Preparando Professores para Promover a Inclusão de Alunos com Necessidades Educacionais Especiais. Londrina. 2009. Disponível em: $<<$ http://www.diaadiaeducacao.pr.gov.br/portals/pde/arquivos/2496-8.pdf $>$. Acesso em: 17 jan. 2020.

OLIVEIRA, Clarissa Tochetto de \& DIAS, Ana Cristina Garcia. Psicoeducação do transtorno do déficit de atenção/hiperatividade: o que, como e para quem informar? Temas em Psicologia, v. 26, n. 1, p. 243-261, 2018.

OLIVEIRA, Maria Márcia Costa. Alfabetização visual: uma abordagem arte-educativa para a contemporaneidade. Estudos Semióticos. Disponível em: 〈http://www.fflch.usp.br/dl >. Acesso em: 25 de jul. 2019.

OLIVEIRA, Marli da Silva de. 2014..Educação Inclusiva Agora. 131f. Monografia (Licenciatura em Artes Visuais) - Universidade de Brasília, Pimenta Bueno-RO, 2014.

OLIVEIRA, R. M. N; FERRARI, B. B. S.O professor e a inclusão do aluno com Déficit de Atenção Hiperatividade, $2014 . \quad$ Disponível em: <http://www.diaadiaeducacao.pr.gov.br/portals/cadernospde/pdebusca/producoes_pde/2013/2 013_uenp_edespecial_artigo_rosilaine_maria_do_no_oliveira.pdf $>$. Acesso em: $17 \mathrm{de} \mathrm{fev}$. 2019.

PEREIRA-SILVA, Nara Liana et al. O papel do psicólogo escolar: Concepções de professores e gestores. Psicologia Escolar e Educacional, v. 21, n. 3, p. 407-415, 2017.

PIMENTA, Selma Garrido; LIMA, Maria do Socorro Lucena. Estágio e Docência. $2^{\circ}$ ed. São Paulo: Cortez, 2004.

PRADO, D. G. A. et al. Dislexia e distúrbio de aprendizagem: histórico familial. DistúrbComun, São Paulo, v. 24, n.1, p.77-84, abril, 2012.

REIS, G. V. Alunos Diagnosticados com TDAH: reflexões sobre a prática pedagógica utilizada no processo educacional. Parnaíba. 2011. Disponível em: <http://www.uems.br/portal/biblioteca/2011-12-15_13-12-05.pdf $>$. Acesso em: $01 \mathrm{fev}$. de 2019.

RIBEIRO, Joice Alvares \& DE MELO, Daniele Santana. O Lúdico No Processo Ensino Aprendizagem Do Aluno Com Transtorno De Déficit De Atenção E Hiperatividade (TDAH). Encontro Internacional de Formação de Professores e Fórum Permanente de Inovação Educacional, v. 11, n. 1, 2018.

RIBEIRO, Maria Luisa Sprovieri. Educação Especial: Desafio de Garantir Igualdade aos Diferentes. PICONEZ, Stela C. Bertholo (Coord.). A prática de ensino e o estágio supervisionado. Campinas, SP: Papirus, 2015.

ROCHA, Margarette Matesco \& DEL PRETTE, Zilda Aparecida Pereira. Habilidades sociais educativas para mães de crianças com TDAH e a inclusão escolar. Psicologia Argumento, v. 28, n. $60,2017$. 
Por uma educação inclusiva: desafios do Transtorno de Déficit de Atenção com Hiperatividade Victória Caroline Vidal; Carlos Daniel Rodrigues de Oliveira; Bruna França Oliveira; Carla Milena de Moura Laurentino; Rahyan de Carvalho Alves

ROLDÃO, M.C. Diferenciação curricular e inclusão. Campinas, SP: Papirus, 2003.

ROTTA, NewraTellechea; OHLWEILER, Lygia \& RIESGO, Rudimar dos Santos. Livro, Transtornos da Aprendizagem, Abordagem Neurobiológica e Multidisciplinar. Grupo A, 2006.

ROSA, Jeâni Kelle Landre \& WEIGERT, Célia; DE ABREU SOUZA, Ana Cristina Gonçalves. Formação docente: reflexões sobre o estágio curricular. Ciência \& Educação (Bauru), v. 18, n. 3, p. 675-688, 2012.

ROGALSKI, Solange Menin. Histórico do surgimento da educação especial. Revista de Educação do IDEAU, v. 5, n. 12, 2010.

SANCHES, Isabel. Compreender, Agir, Mudar, Incluir. Da investigação-ação è educação inclusiva. Rev. Lusófona de Educação, Lisboa, n. 5, p. 127-142, 2005.

SILVEIRA, Flávia Furtado; NEVES, M. M. B. J. Inclusão escolar de crianças com deficiência múltipla: concepções de pais e professores. Psicologia: teoria e pesquisa, v. 22, p. 79-88, 2006.

SANT'ANA, Izabella Mendes. Educação inclusiva: concepções de professores e diretores. Psicologia em estudo, v. 10, n. 2, p. 227-234, 2005.

SMITH, C.; STRICK, L. Dificuldades de aprendizagem de A a Z. Porto Alegre: Artmed, 2001.

SOARES, Jeise do Carmo Bruno; SOUZA, José Camilo Ramos de. Geografia e arte: artes plásticas como recurso didático no ensino de geografia $6^{\circ}$ ano do fundamental na Escola Estadual Gentil Belém. TCC (Geografia). CESP-UEA, [S.1.], 2017.

SOARES, Aline Raquel de Lima; MATOS, Ana Carolina Nunes de. O TDAH em alunos do ensino fundamental I. Psicologia. Olinda - PE, p. 1-14, 26 nov. 2017.

SCALABRIN, Izabel Cristina \& MOLINARI, Adriana Maria Corder. A importância da prática do estágio supervisionado nas licenciaturas. Revista Unar, v. 7, n. 1, p. 3, 2013.

SPINNLER, C; CAMPOS, S. O; MATOS, J. O. O Transtorno do Déficit de Atenção e Hiperatividade (TDHA): Desafios e Contribuições para Pais e Educadores. Psicologado, 2019. Disponível em: 〈https://psicologado.com.br/psicopatologia/transtornos-psiquicos/transtorno-dodeficit-de-atencao-e-hiperatividade-tdah-desafios-e-contribuicoes-para-pais-e-educadores > . Acesso em: 03 jan. 2020.

UNESCO. Declaração de Salamanca. Conferência mundial sobre necessidades educativas especiais: acesso e qualidade. Salamanca, Espanha, 7-10 de Junho de 1994, UNESCO, Lisboa: Instituto de Inovação Educacional, 1994.

UNESCO. TRANSTORNOS MENTAIS, Estatístico.

DSM-5. AMERICAN

PSYCHIATRIC ASSOCIATION-APA. Porto Alegre: Artmed, 2014. 
Por uma educação inclusiva: desafios do Transtorno de Déficit de Atenção com Hiperatividade Victória Caroline Vidal; Carlos Daniel Rodrigues de Oliveira; Bruna França Oliveira; Carla Milena de Moura Laurentino; Rahyan de Carvalho Alves

VYGOTSKY, Levi S. A. formação social da mente: O desenvolvimento dos processos psicológicos superiores. 5 ed. São Paulo: Martins Fontes, 1994.

VITTA, Fabiana Cristina Frigieride; VITTA, Alberto de; MONTEIRO, Alexandra S.R. Percepção de professores de educação infantil sobre a inclusão da criança com deficiência. Revista Brasileira de Educação Especial. Associação Brasileira de Pesquisadores em Educação Especial, v. 16, n. 3, p. 415-428, 2010. 